\title{
Study on Interactive Urban Public Art in the Background of Big Data Liyuan $\mathrm{Li}^{1, \mathrm{a}^{*}}$ and Mengxue Luo ${ }^{1, \mathrm{~b}}$ \\ ${ }^{1}$ School of Art and Design,Wuhan University of Science and Technology, China \\ a181173081@qq.com, ${ }^{b} 568618159 @ q q . c o m$
}

Keywords: Interactive Art; Public Art; Urban

\begin{abstract}
With the advent of Age of Experience Economy and the rapid development of digital virtual technology, interactivity is gradually introduced and integrated into art design. Public urban artworks are becoming increasingly interactive, which brings more and more vitality to city space. Based on the clarification of the concepts of Interactive Design, Public Art and Interactive Public Art, the paper analyzes four features of Interactive Public Art: interactivity, technologicalness, dynamism and interestingness, and puts forward methods of the realization of interactive urban public art, including concept transition from concrete entity creation to experience-oriented design, method transition from individual creation to collective creation, and the introduction of digital virtual technology.
\end{abstract}

\section{Introduction}

Social and economic development in China accelerates the process of urbanization, in which public art draws increasing concerns as people in city exert higher demand for aesthetic experience and psychological satisfaction. The overall public art in a city, to some extent, represents a city' $\mathrm{s}$ image and cultural heritage. Excellent public art works should embody the spirit of a city and the time so as to be accepted and integrated into its cultural tradition and finally become a part of its history. [1]With the application and popularization of new media technology, more and more new art forms is emerging in the process of modern public artistic creation. Different from traditional art forms with physical and unchangeable identity like sculpture and mural, the new ones display richer variations through the introduction of new media technology into the field of public art. For example, the virtual reality technology (VRT) provides a new display measure for public artistic works and meanwhile endows them with dynamic and multidimensional features.

\section{Concepts of Interactive Design, Public Art and Interactive Public Art}

Interactive design came into being since the 1960s and the earliest design, human-computer interaction, aimed to provide a simple interface for ordinary users to operate computers and other emerging digital products more easily. Richard Buchanan defines interactive design as a practice to motivate and support human action via media, including physical and virtual products, service and system. [2]According to the definition, interactive design is firstly a human-oriented action. The literal meaning of "interaction" implies that it is a mutual action, and since the happening of an action requires people, tool (media), purpose and context, these five are regarded as essential components in interactive design.

The concept of public art arose in the U.S.A in 1960s, but it was until the 1990s that it started to attract attention from academic field in China. There is no universal agreement on the definition of public art until now. Generally speaking, public art is equipped with following several features. First, public art are visually shared by all the people instead of privileged minorities. Second, the place in which public art works locate, whether physical place such as street, plaza and park or virtual net world, belong to the public space. Third, public art embodies property of public participation since it originates from democracy.[3]

Interactive public art is an important subfield of modern interactive art, which is an art form that allows viewers to participate. Most of the interactive works of art respond to the action of the audience via computer, interface, and sensors. Interactive public art refers to an art form equipped with the 
function of interaction by introducing digital virtual technology or the involvement of the public into the field of public art.

\section{Features of Interactive Urban Public Art}

Compared with traditional public art, interactive public art is equipped with four new features: interactivity, technologicalness, dynamism and interestingness.

Interactivity: the Essential Characteristics of Interactive Public Art. Different from traditional public art, which only provides visionary impression for audience, interactive public art will leave an access for the audience to interacting with the surrounding. Interactive Metal Ball in Germany Pavilion of the Shanghai World Expo is an example of interactive design encouraging the audience's involvement. When the visitors shouted in unison, the big metal ball started to swing. The more loudly they shouted, the higher the metal ball swung. The secret lies in the fact that a system of voice-operated device is installed in the base of the metal ball to control its movement in accordance with outside environmental change.

Technologicalness: the Basis for the Realization of Interactive Public Art. The use of virtual reality technology and mechanical control devices make it possible for public art to create interactive environment. The Crown Fountain, designed by the Spanish artist Jaume Plensa, introduces new media technology, which integrates water with electronic video, LED lamps and other modern technologies, into the public environment. The overall design of Crown Fountain displays a strong modern feature. Two electronic display tower, up to 15.2 meters high, consist of more than 1 million LED tubes and each tower is equipped with 147 electronic screens comprising 264480 LED lights inside, which embodies high-tech feature of the public art.[4]

Dynamism: an Important Feature of Interactive Public Art. Interactive public art has got rid of rigidity and staticness of traditional public art and becomes more dynamic. Cloud Gate, designed by Anish Kapoor, is static from physical perspective, but it brings the audience a sense of dynamism by reflecting images on the bright and clean surface and from different angles visitors will experience ever-changing urban landscape.

Interestingness: Prominent Feature of Interactive Public Art. In the process of interacting with modern public art, the audience will certainly receive some feedbacks, most of which are interesting. The Piano Staircase at the Odon Plains Subway Station in Stockholm, Sweden, is shaped as a big piano keyboard and under each key a pressure sensor is installed and connected to a loudspeaker. When people go up or down the stairs, each step of a visitor is like a strike on a giant piano and different steps will trigger different notes, so going up and down the stairs becomes an entertaining experience instead of tiresome job, which has encouraged many people from taking escalator. Soon the design becomes very popular and widespread to the whole world. Up to now, similar designs have come into being in Nanjing, Hangzhou and Zhengzhou in China.

\section{Realization of Interactive Urban Public Art}

Concept Transition from Concrete Entity Creation to Experience-oriented design . Interactive public art is different from traditional sculpture and murals. The latter focuses on concrete entity, emphasizing the form, style, material and shape of art works. Interactive art highlights audience-oriented experience, and through mutual interaction audience are integrated into the art works as an essential components. [5]Peep, a typical example of interactive public art created by Chen Jian and Cai Shuying, applies projectors, cameras, screens and other equipments on the inside and outside of Taipei MRT station platform to trigger a new experience in audience by allowing them to peep at other people's behavior and at the meantime to be peeped at by other people. [6]Empty Room , created by Maya Lin, also emphasizes audience-oriented experience through mutual interaction. Empty Room, installed in the underground exhibition hall of Museum of Contemporary Art Beijing, is not a purely physical room but a systematic multi-media device appealing for the protection of endangered wild life and the environment. The audience can walk into the room, pick up a piece of optical plastics, catch an virtual 
animal in their hands, in a way a form of real animal in human's hand, and be taught about endangered wildlife by floor-embedded apparatus. During the process, audience will consider the relationship between those endangered wildlife and the environmental destruction made by human being.

Method Transition from Individual Creation to Collective Creation.To arouse people's interest in involvement into creation of public art works, the creative method should change from individual model to collective model. Joseph Beuys' 7000 Oaks is an example in which the public are invited into art creation through socially conscious organizations that merge art, education, and environmental issues in their work. The project started with the first planting tree by Joseph Beuys, and later with the help of volunteers in different occupations, 7,000 oak trees were planted over several years in Kassel, Germany, each with an accompanying basalt stone. The project has become the greatest public art work in Kassel and a masterpiece in the history of public art and its significance lies in acknowledging the creativity inherent in volunteers by encouraging them to plant trees on their own. The volunteers were participating in the whole creation process and even became main creator after the author hid from the scene. They are no longer visitors but a basic element of the project the moment they started to plant the trees. Through inviting the public into the creation, Beuys changes traditional relationship between the author and the public in art creation. [7]The public changes from indifferent visitors into cooperative partners. The interactivity, emphasized by modern public art, will enable art to blend into the common life of the public and thus construct an interface between the author and the public to exchange inspiring ideas in which art works will be maximized to the full value.

The Introduction of Digital Virtual Technology. The advent of Digital Virtual Technology redefines the traditional form of public art and makes simultaneous interaction between the art works and the audience possible. Maya Lin's Map of Memory in her serial project What is Missing, different from her former works of physical monuments, employs DVT extensively to arouse the public attention and awareness of the warning of Sixth Great Extinction of Wildlife.[8] Map of Memory exists in the virtual cyberspace and consists of world atlas and scattered colorful dots standing for disappeared or disappearing species and natural phenomena. Click a dot and the audience will be led to a linked message, picture or video of an endangered species. [9]Also people are allowed to input into the resource bank related information about disappearing species they notice, which means that every visitor is allowed to be one of the creators of Map of Memory.

\section{Summary}

With the advent and development of interactive public art, the public are no longer just an appreciator of art works. Visitors can communicate with artworks and their authors when they appreciate them, and even become co-creators of the artworks. Confronted with the rapid progress in the field of public art, artists are required to shift their attention from "physical entity" to "audience experience" , integrate digital virtual technology into the process of the creation and improve the interaction between the public and artworks. Only through the joint effort of the public and artists can vitality be instilled into the field of urban public art to enrich the life of citizens.

\section{Acknowledgements}

Financial support for this work, provided by:Humanities and Social Science Research Project, Hubei Provincial Department of Education, NO16Q041.

\section{References}

[1] F.Wang: The Research on the Interactive Design of City Public Art under the Background of Digital Age(Ph.D., Jiangnan University, China 2010), p.3. (In Chinese)

[2] X.Y.Xin: Design,(2011)No.2:p.45-47. (In Chinese)

[3] H.Li: Decoration,Vol.286(2017)No.2:p.70-72. (In Chinese) 
[4] Y.Zhang: Journal of Nanjing Arts Institute (Fine Arts \& Design),(2011)No.4:p.148-151. (In Chinese)

[5] Information on http://www.wendangwang.com

[6] Y.Shu: Packaging Engineering,(2016)No.06:p.93-96. (In Chinese)

[7] L.Z.Huang: New Arts,(2013)No.05:p.74-77. (In Chinese)

[8] Lauren R. Kolodziejski: Environmental Communication,(2015)No.4:p.428-445.

[9] Information on http://whatismissing.net 